Article

\title{
A Perspective on Biotribology in Arthroplasty: From In Vitro toward the Accurate In Silico Wear Prediction
}

\author{
Saverio Affatato ${ }^{1, *(1)}$ and Alessandro Ruggiero ${ }^{2}(\mathbb{C}$ \\ 1 Laboratorio di Tecnologia Medica, IRCCS Istituto Ortopedico Rizzoli, Via di Barbiano, 1/10, \\ 40136 Bologna, Italy \\ 2 Department of Industrial Engineering, University of Salerno, Via Giovanni Paolo II, nr. 132, 84084 Fisciano, \\ Italy; ruggiero@unisa.it \\ * Correspondence: affatato@tecno.ior.it; Tel.: +39-051-6366864; Fax: +39-051-6366863
}

Received: 26 July 2020; Accepted: 8 September 2020; Published: 10 September 2020

\begin{abstract}
Nowadays hip arthroplasty is recognized as one of the most successful orthopedic surgical procedures, even if it involves challenges to overcome, such that lately, younger and more active patients are in need of total arthroplasty. Wear is still one of the main issues affecting joint prostheses endurance, and often causes loosening accompanied by implant failures. Actual in vitro wear tests executed by mechanical simulators have a long duration, are very expensive, and do not take into account all the possible daily activities of the patients; thus, the challenge to obtain a complete in silico tribological and dynamical model of (bio) tribo-systems could give the possibility to overcome the actual testing procedures and could contribute as a tool for a more accurate tribological design of human prostheses. This prospective paper is intended to underline actual research trends toward the challenge of having accurate numerical algorithms to be used both in preclinical testing and in the optimizations of the prostheses design. With this aim we depicted the possible in silico approach in artificial joints' wear assessment over time, accounting for contact mechanics, numerical stress-strain analysis, musculoskeletal multibody, and synovial lubrication modelling (boundary/mixed, hydrodynamic, and elastohydrodynamic).
\end{abstract}

Keywords: biotribology; wear measurement; in silico; hip arthroplasty; synovial lubrication

\section{Introduction}

The number of hip joints, as well as the amount of economic resources dedicated to this surgery, are constantly growing in Italy [1]. This surgical procedure, thanks to the excellent clinical results obtained in the last years, hurriedly evolved to solve degenerative diseases on the skeletal joints. After total or partial joint replacements, the articular functions are fully restored and the patients return to a pain-free condition [2]. In this framework it becomes necessary to guarantee that new prosthetic designs (geometry and materials) have to be deeply analyzed and tested before the clinical trials begin. Joint implants, developed for the human body, require special considerations of safety and accuracy. A preclinical validation of these medical devices is necessary in order to establish their resistance to the wear. During these tests, particular attention is devoted to the analysis of the biocompatibility of the biomaterials used [3], as well as analyzing any undesirable biological phenomena caused by the interaction of biomaterials used for the realization of the device with body tissues [4]. The validation of a new joint design is linked to the improvement of performances both from a biomechanical and tribological point of view. In addition, new medical devices are tested in clinical trials to confirm that the prototype does not compromise the patient. Moreover, these new medical devices have to provide the expected results despite the physiological and pathological variability of the target population. 
In recent years, many efforts have been made to improve both biomaterials and the design of new prosthetic couplings. The fundamental tools for the evaluation of a prosthetic design are the multicentric outcome registries [5,6]. These registries offer important information regarding any complications or event related to a joint prosthesis. These registries are an indispensable tool for analyzing the behavior of prostheses based on the evidence of criticality observed. Considering the wide range of implants and surgical techniques, the differences in the performances of the different prosthetic solutions can be observed as statistically significant only if many national centers enrich their registries.

A new and modern trend for the validation of prosthetic devices is to use biomechanical and tribological models for the characterization of prosthetic contacts. This approach can be carried out through the development of theoretical and numerical computational models validated through in vitro experiments. In recent years, several theoretical and numerical models have been proposed in order to interpret every possible scenario in vivo; these models constitute a first step toward the preclinical validation of prostheses with a reduction of budgets and times $[7,8]$.

With the aim of highlighting actual research trends toward the challenge of having accurate numerical algorithms to be used both in preclinical testing and in the optimizations of the prostheses design, in this paper we depicted the actual scientific framework on the in silico wear assessment in artificial joints, focusing on underlining the role of contact mechanics, numerical stress-strain analysis, musculoskeletal multibody, and synovial lubrication modelling (boundary/mixed, hydrodynamic, and elastohydrodynamic) in the numerical algorithms.

\section{In Vivo Wear Testing}

It has just been described how the need to eliminate or reduce wear in joint replacements is of great importance for the reduction of revision rates. This can be achieved by deeply understanding the mechanisms of implant tribology using in vitro and in vivo experiments. In vivo (word derived from Latin meaning "within the living") refers to the experimentation developed in living organisms as opposed to those conducted on parts of the organism or in corpses. In vivo tests are often accompanied by in vitro tests to observe the overall effects of an analysis. Translating these concepts into the orthopedic field, many wear assessment procedures are used to evaluate the in vivo performance of a prosthesis [9]. The most used diagnostic methodology for the monitoring of wear and osteolysis is the radiographic one $[10,11]$. Radiographs are usually used to determine clinical wear by assessing the degree of penetration of surfaces in contact. For example, in the assessments concerning hip prostheses, the penetration of the femoral head into the acetabular cups can be assessed using a compass necessary to identify the position of the minor eccentricity found. Hence, linear wear is the difference between the initial postoperative radiography and the most recent radiography measured in millimeters $[9,12]$.

However, traditional imaging techniques such as conventional radiographs, are limited by poor contrast resolution and specificity [13]. In addition, magnetic resonance imaging (MRI) or radiostereometric analysis (RSA) could be considered as additional techniques in the orthopedic field. In particular, MRI is commonly used in body composition research to measure whole body skeletal muscle mass $[14,15]$. MRI calculation methods can vary by analyzing the images at different slice intervals (or interval gaps) along the length of the body [15]. The RSA is used in the orthopedic field to measure the translations/migration of joint replacement components with respect to the host bone in vivo [16-18]. This kind of application is able to detect early stages of particle disease before osteolysis is apparent on radiographs. Obviously, the precision and accuracy of the method should be determined from time to time when a new anatomical area or a new prosthetic design is considered. In particular, precision is equal to repeatability and defined as the agreement between two test results under the same conditions; the accuracy, instead, is the "trueness" of a measurement, and it is defined as the closeness of agreement between a test result and a known value [17-19]. In particular, Seehaus and colleagues [20] suggest that RSA is an alternative method for in vivo measurement of implant migration; they found an accuracy that ranged from -0.048 to $0.037 \mathrm{~mm}$, and $-0.057^{\circ}$ to $0.078^{\circ}$ or translation and 
rotation respectively. In agreement, Önsten et al. [18] found a precision of $\pm 0.045 \mathrm{~mm}$ by using the RSA technique in the measurement of THR femoral component translations.

These kinds of applications, including the evaluation of growth plate integrity, joint kinematics, and implant stability, may be successfully undertaken in patients following total hip/knee replacement, and are considered as the most accurate in which the magnitude of relative displacements of prosthesis is determined from radiographic images [21,22].

\section{In Vitro Wear Testing}

The prevalence of primary and revision total hip arthroplasty is increasing constantly. By 2030, the demand for primary total hip arthroplasties, performed in the United States, is estimated to grow by $174 \%$ to 572,000 [23]. According to studies by Kurtz and collaborators [19], the demand for hip replacement reviews is expected to grow by $137 \%$ and $601 \%$, respectively, between 2005 and 2030; this is linked to an increase in the demand for total hip and knee arthroplasty. The economic consequences of these demands on hospitals are burdensome $[24,25]$. Since total joint replacement has been applied to younger and more active patients, current limitations are related to the rapid wear of the components. The purpose of research in tribology is, reasonably, the minimization or elimination of wear in joint tribo-systems. Wear is a phenomenon in which the worn material is expelled from the contact between two surfaces in the form of debris of particles. The expelled debris can cause unwanted issues in the tissues and can cause loss of bone mass around the implant with consequent loosening of the fixation [26]. Testing methods in science are traditionally called by their Latin names: in vitro comes from the Latin term "in glass" [27]. In particular, the term refers to studies of biological properties that are done in a tube rather than in a human or animal. This testing method involves experiments on biological matter (cells or tissues) outside of a living organism. The reference to glass is quite literal: in vitro experiments were historically conducted in a Petri dish.

However, in vitro studies allow scientists to perform experiments that are also less expensive and can be done with fewer ethical and safety concerns. In vitro studies play an important role across all fields of medical research.

In particular, research based on in vitro experiments is important in the preclinical validation of medical devices. This test must be regulated for the construction of a new medical device, which must be safe in order to be implanted in patients. The characterization of a new biomaterial can be performed according to the phases represented in the diagram in Figure 1.

Biological and mechanical screening tests must be performed on the new biomaterials that are to be used in joint prosthetic implants in order to obtain the required quality control. Furthermore, wear tests must be performed, before clinical adoption, in order to acquire knowledge on the tribological phenomena that occur [28]. In experimental measurements, the physical laws govern the system and the simulation can represent the most realistic conditions of use. In this context, two categories of laboratory wear test equipment are common [28]:

- The so-called quick tests, which provide information exclusively on the intrinsic features of the materials studied. These wear tests can be performed in dry and lubricated conditions and in different configurations. Measuring friction, wear, and material mechanical properties is a way for engineers to understand how materials will stand up to the rigors of biomedical application. These wear tests are fast and cheap but, unfortunately, they do not accurately reproduce the contact geometries and the kinematics of the real prostheses [29]. A schematic representation is given in Figure 2.

- Vice versa, the hip and knee joint wear simulators are machines in which real prostheses are mounted on these apparatuses, as intended in vivo, and tested in an environment that simulates physiological conditions. These simulators can reproduce a simplified level of walking, as specified in international guidelines [30,31]. Recently, efforts are devoted to the simulation of a more demanding task that would reproduce the wear rates of daily living activities [32,33]. A schematic representation is given in Figure 3. 


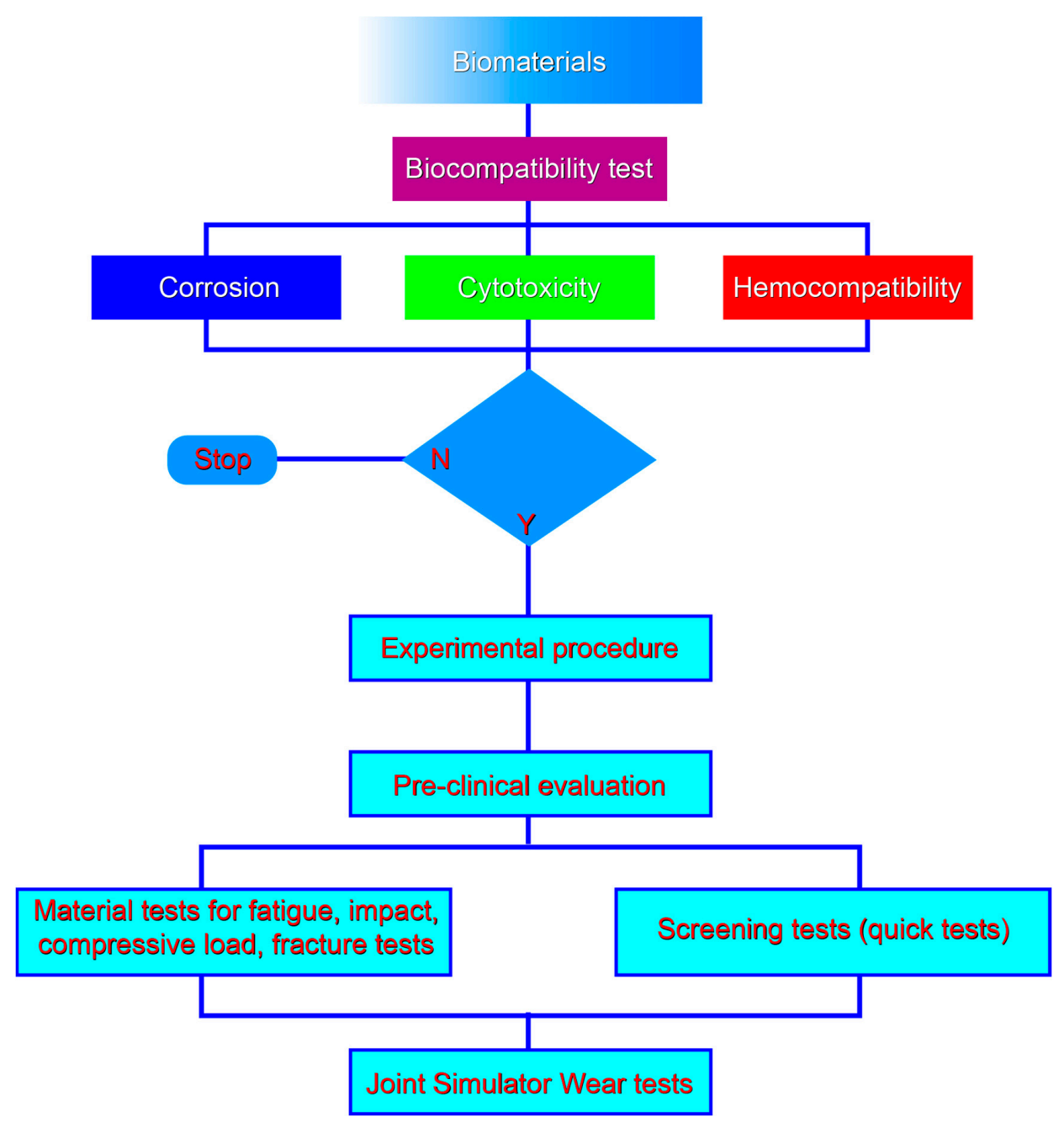

Figure 1. Flow chart showing the characterization of a new biomaterial.

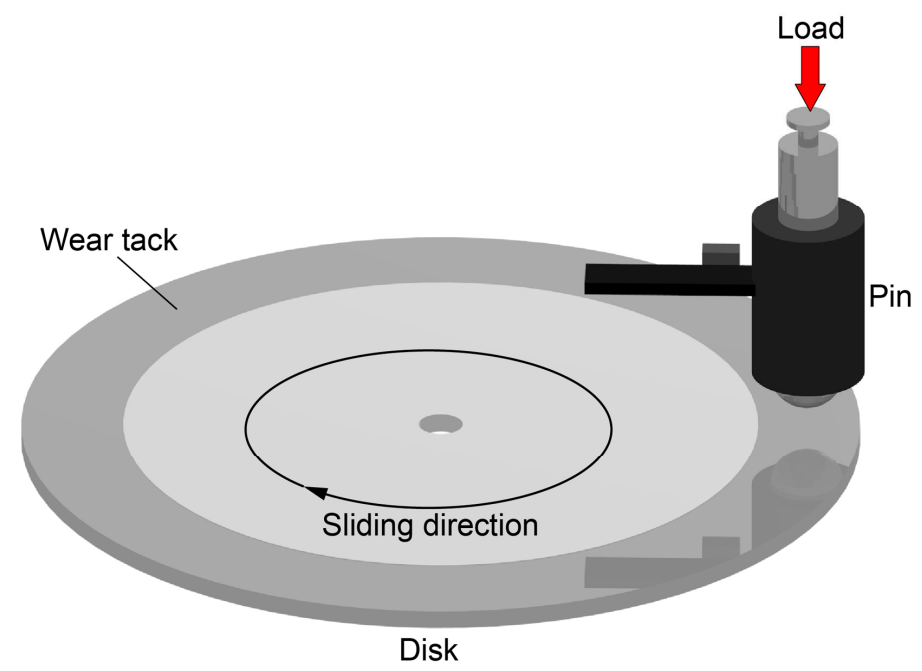

Figure 2. Schematic representation of the pin on disk tests. In particular, the pin is pressed against a rotating disk under the given load. The pin can be of any shape; however, the most popular shapes are spherical or cylindrical. 


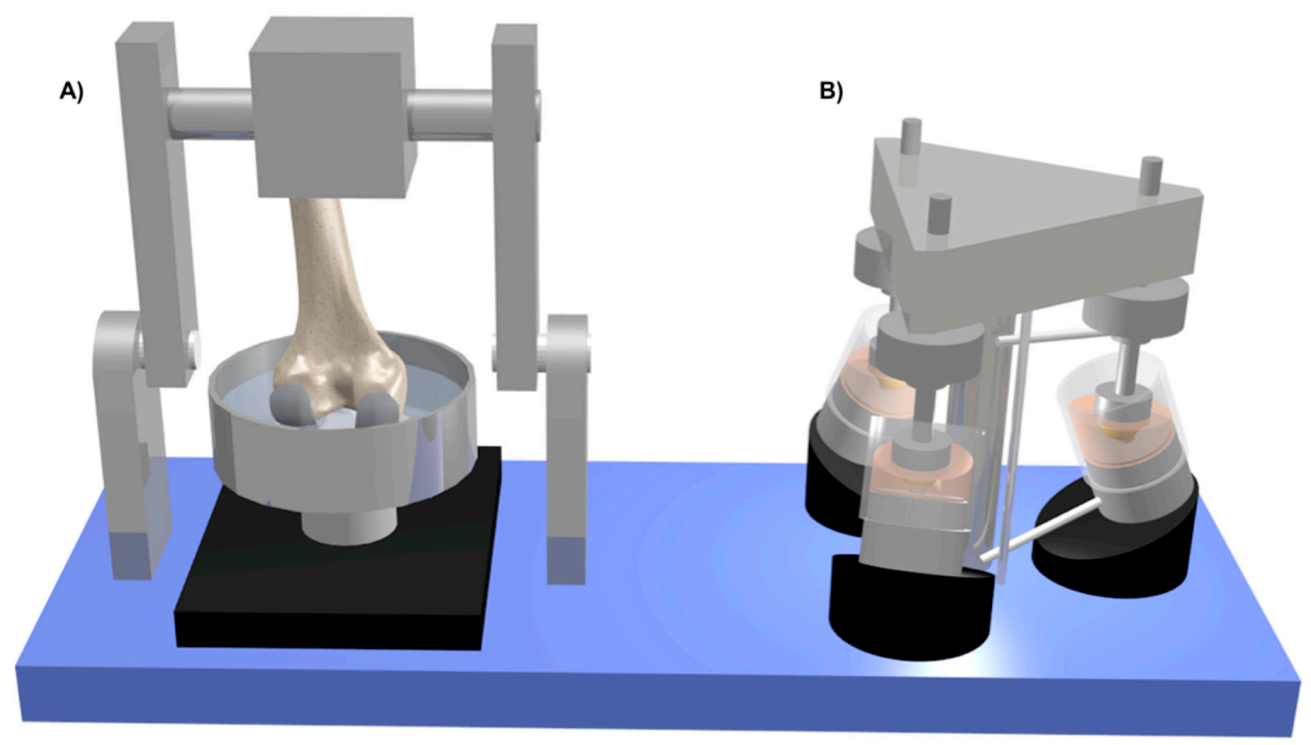

Figure 3. Schematic representation of the so-called knee and hip joint simulators. In (A) a schematic station of a knee joint simulator; in (B) a schematic station of a hip joint simulator. This picture is a general view for joint simulators and not a representation of displacement or force control, or anatomical or upside-down positioning of the prostheses.

Experimental tribological simulation apparatus of knee and/or hip prostheses behaviors have increased over the years in order to be able to reproduce tribological wear tests in which the biomechanics of human joints, under controlled conditions, are replicated fairly faithfully [30-33]. The simulators of the hip and knee joints play a fundamental role in the preclinical validation phase of a medical device [34]. They simulate, in a controlled environment, what happens on a real implanted prosthesis. Knowledge of the wear rate and wear mechanisms even in the presence of synovial fluid are of great importance in the preclinical validation process [35].

The objectives of wear tests are to determine the wear rate and its dependence on the test conditions (i.e., load, range of motion, lubricant, and temperature). In the last years, efforts have been made by scientists to better quantify the in vitro wear assessments. From the historical and considered "gold standard" method to measure the weight loss from bearing systems (the gravimetric method), we have evolved toward more wear methods that have taken into account the damage on a prosthesis due to its surface finishing and change of shape by using the coordinate measuring machine (CMM) or the more recent 3D optical wear assessment. More details are available in international literature [36,37].

\section{Toward the In Silico Wear Test}

In vitro studies play an important role across all fields of medical research, thus biomedical manufacturers have started with computer modelling and simulation. In this way they accelerate their product development processes and reduce the huge cost of bringing a new device to the market. Today, to maintain the exponential growth of innovation, the medical and pharmaceutical worlds are entering an era in which a growing number of experiments will be done on the computer to complete and accelerate in vivo and in vitro approaches. This has the potential to revolutionize science and medicine. Advanced computer modelling techniques (often referred to as in silico models), is an expression used to mean "performed on computer or via computer simulation" [38]. The expression in silico "appears" for the first time in 1989 in the workshop "Cellular Automata: Theory and Applications" in Los Alamos, New Mexico [39,40]. The experimental tribological devices for the simulation of hip and knee prostheses have been improved over the years in order to make them able to reproduce tribological wear tests in kinematic and dynamic conditions very close to the real ones [30-33]. The new trend of an in silico approach to the evaluation of the articular prostheses' wear represents, nowadays, 
a fascinating scientific challenge, which involves many disciplinary fields and which requires a deep collaboration between scientists from different areas [41-44].

One of the most current in silico approaches is represented in Figure 4 with reference to the total hip replacement. With the aim to calculate the hip wear, taking into account the complex tribological phenomena acting in the artificial synovial joints, the proposed approach follows the scheme in Figure 4.

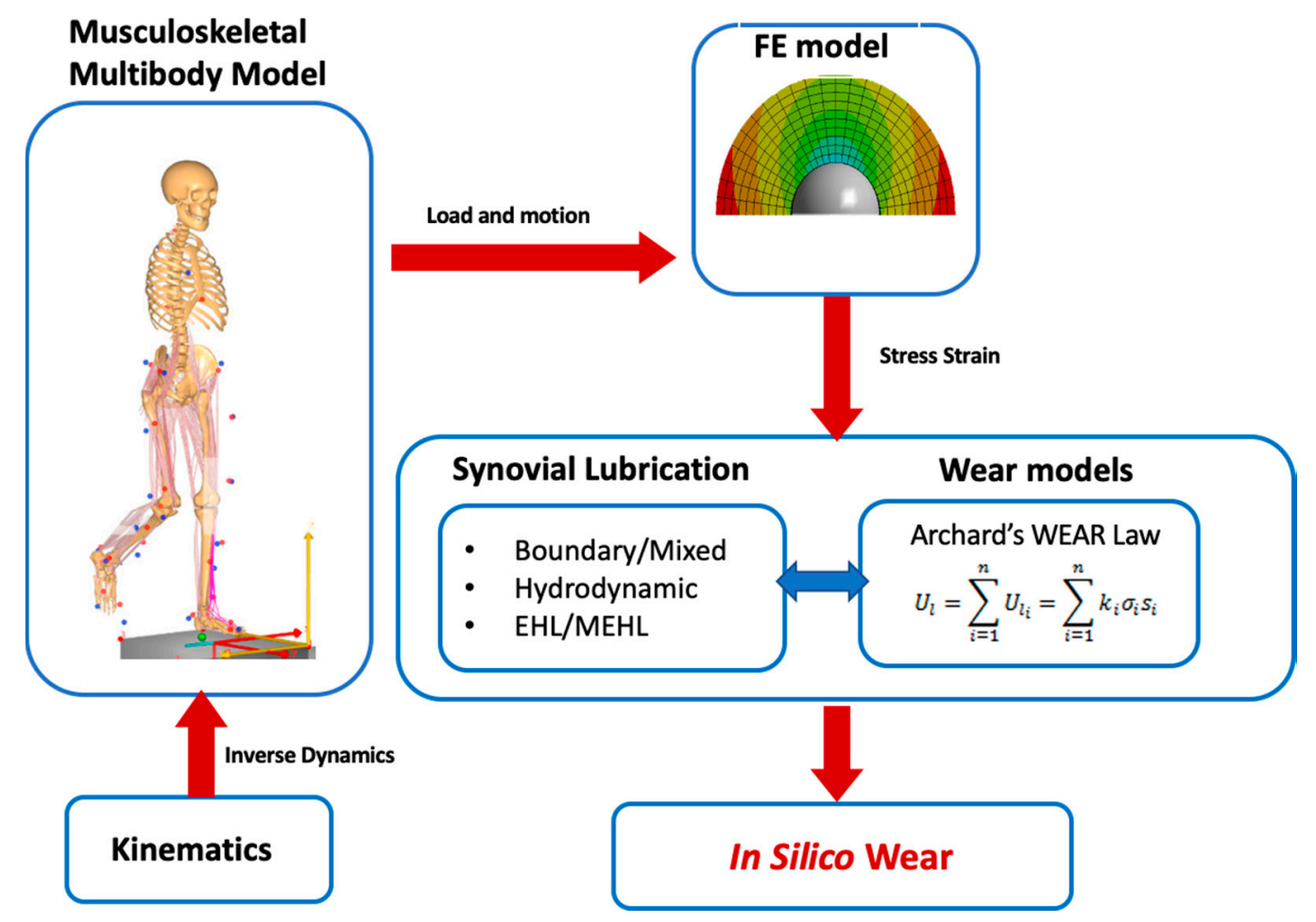

Figure 4. Flow chart showing the tribological phenomena acting in an artificial synovial joint.

The in silico procedure starts by evaluating the human motion kinematics in the framework of inverse dynamic analysis (motion capture) with reference both to normal gait and other desired daily activities [32,45]. The obtained data are used for the calculation of the unsteady joint forces which are used as load conditions in joint Finite Element Analysis (FEM) [42-44]. The resulting stress-strain behavior of the artificial coupling have to be joined with the lubrication model for taking into account the complex synovial phenomena acting in the joint $[41,46]$. Once the lubricating film is modelled, suitable wear models will furnish the possibility to obtain the in silico wear values for the investigated artificial joint.

Of course this fascinating approach needs more accurate mathematical models in order to depict in an accurate way the real phenomena acting in the considered tribo-system. Many models which were proposed in literature are from a synovial lubrication point of view; in these models a combination of Boundary Lubrication (BL), Mixed Lubrication (ML), Hydrodynamic Lubrication (HL), and Elasto-Hydrodynamic Lubrication (EHL), are considered [47,48]. The conditions of high loads and low relative motion could lead to a lubricated contact between the articulated surfaces despite their deformation, so that in these contact areas the contact pressure rises and Mixed Elasto-Hydrodynamic Lubrication (MEHL) occurs. Since the gap thickness values reached in this lubrication model are very low, the lubricant viscosity could be affected by the high pressure developed in the gap, so appropriate relationships between viscosity and pressure are necessary in the modelling of the non-Newtonian synovial fluid behavior [49]. The Archard wear equation [50] represents a simple and effective model for the description and calculation of wear. It does not take into account variations in the properties of materials on the surface. This equation provides an approximation and assumes that the linear wear rate is directly proportional to the contact pressure. More recently, Mazzucco and collaborators [51] 
have argued that there is no apparent relationship between the rate of wear depth and the contact pressure (i.e., independent quantities). The work of Kang et al. [52] argues that there is an inverse relationship between wear and contact pressure. O'Brien et al. proposed an interesting theory based on energy dissipation: the process of wear is inherently dynamically adaptive, and localized high wear can result in faster deformation in certain locations, thus altering the surfaces of the articulating geometries and altering the kinematics and contact pressure distribution for subsequent cycles $[53,54]$.

\section{Research Directions}

The new challenge for scientific research in the tribological and orthopedic field is to improve preclinical methodologies by proposing integration between computational and experimental methods. Testing medical devices in their working environments is necessary, and recently new areas of tribology have emerged, such as nanotribology, wear, and lubrication at the nanoscale level $[55,56]$, biotribology (which deals with human joint prosthetics [57,58]), and lubrication and wear [59]. Moreover, studies of superlubricity, i.e., the mechanisms responsible for extremely low friction [20-23], have created great expectations for energy saving, and the creation of graphene is also greatly promising in this direction [60-62]. However, once the in vitro results have been validated, the in silico methods could be used more effectively to provide a set of preclinical analysis tools enhanced towards an optimal tribological design of the artificial joints. For doing this, more and more accurate theoretical and numerical models have to be investigated and developed, by taking into account all the possible phenomena acting in the real tribological contact [63]. Even if, in the last decades, the progress toward this aim has continued, open research problems still exist. Recently, regulatory authorities such as the U.S. Food and Drug Administration (FDA) have recognized the value of computer modelling and simulation within their approval processes when simulation is properly applied [64,65]. With reference to the in silico tribological modelling of total/partial joint replacements, attention should be paid, first, to the accurate definitions of the acting loads on the joints during several kinds of human daily activities, which should be obtained by using more sophisticated musculoskeletal multibody models, as suggested in previous studies [66]. From the lubrication modelling point of view, detailed contact and wear models should be investigated, also on the micro-scale, and tribo-corrosive phenomena (if any) should be considered [49], in which the contact surfaces' topographies could play a key role in the rupture of the thin synovial fluid film, in particular load/kinematical conditions. Connected to this issue, with reference to ceramic components, also the observed metal transfer phenomena should be investigated and predicted, allowing the description of the surface modifications during the prosthesis' life in the lubrication modelling.

Clinical research in the joint prosthetic field, with the aim of evaluating the performance of new biomaterials from a tribological point of view, is essential to prevent the onset of unexpected failures [67]. Continuous improvements are needed on the wear tests, which must take into account the tests performed in vitro (using joint simulators) in order to accurately replicate the behavior in vivo. Wear tests on simulators are complicated activities, mainly due to the lack of knowledge of the wear mechanisms in correspondence with the multiple operating conditions. Wear tests can help clarify the wear mechanisms that must be implemented in predictive in silico models. This new objective constitutes a scientific revolution towards in silico that will be able to encourage technological, medical, and pharmaceutical innovation, allowing all interested patients to better conduct their daily activities at an affordable cost.

\section{Conclusions}

This work highlighted current scientific scenarios for the in silico modelling of tribological phenomena in prosthetic joints, with a focus on current approaches, open problems, and future research trends toward more and more accurate models.

The lack of standardization of prosthetic load profiles for daily human activities constitutes an important limitation for the in silico wear tests. It is necessary to have better biomechanical, 
kinematical, and dynamical models to accurately calculate articular loads during the different daily human activities.

The validation of the theoretical/numerical models requires the analysis of the results obtained in vitro, as well as the measure of typical tribological properties, in order to propose increasingly approximate in silico models describing in an accurate way the tribological behavior of joint prosthesis.

Given the high multidisciplinary nature of the research field, there is a need for a deep cooperation between scientists of different areas. In addition, probabilistic methods are able to provide results related to the variability of the phenomena involved, thus multiple factors can be combined in a single model and explored in a statistically robust way.

Author Contributions: S.A. and A.R. conceived and designed the experiments; S.A. performed the in vitro experiment; A.R. performed the in silico analyses; S.A. and A.R. analyzed the data; S.A. wrote the initial draft; S.A. and A.R. contributed to the final version of the manuscript. All authors have read and agreed to the published version of the manuscript.

Funding: This research received no external funding.

Acknowledgments: The authors thank Luigi Lena IRCCS Istituto Ortopedico Rizzoli for the original images in this article.

Conflicts of Interest: The authors declare no conflict of interest.

\section{References}

1. Rizzoli, I.O. REPORT of R.I.P.O. Regional Register of Orthopaedic Prosthetic Implantology Overall Data Hip, Knee and Shoulder Arthroplasty in Emilia-Romagna Region (Italy) 2000-2017. Available online: https://ripo.cineca.it/authzssl/pdf/report_eng_2017.pdf (accessed on 7 September 2020).

2. Viceconti, M.; Affatato, S.; Baleani, M.; Bordini, B.; Cristofolini, L.; Taddei, F. Pre-clinical validation of joint prostheses: A systematic approach. J. Mech. Behav. Biomed. Mater. 2009, 2, 120-127. [CrossRef]

3. Barrère, F.; Mahmood, T.A.; de Groot, K.; van Blitterswijk, C.A. Advanced biomaterials for skeletal tissue regeneration: Instructive and smart functions. Mater. Sci. Eng. R Rep. 2008, 59, 38-71. [CrossRef]

4. ISO-10993 Biological Evaluation of Medical Devices_Part 1: Evaluation and Testing within a Risk Management Process; ISO International: Geneva, Switzerland, 2018.

5. Boyer, B.; Bordini, B.; Caputo, D.; Neri, T.; Stea, S.; Toni, A. What are the influencing factors on hip and knee arthroplasty survival? Prospective cohort study on 63619 arthroplasties. Orthop. Traumatol. Surg. Res. 2019. [CrossRef] [PubMed]

6. Affatato, S.; Cosentino, M.; Castagnini, F.; Bordini, B. Registry study on failure incidence in 1,127 revised hip implants with stem trunnion re-use after 10 years of follow-up: Limited influence of an adapter sleeve. Acta Orthop. 2019, 90, 417-420. [CrossRef] [PubMed]

7. Javierre, E.; Moreo, P.; Doblaré, M.; Garcia Aznar, J.M. Numerical modeling of a mechano-chemical theory for wound contraction analysis. Int. J. Solids Struct. 2009, 46, 3597-3606. [CrossRef]

8. Ferguson, K.A.; Chatzikalymniou, A.P.; Skinner, F.K. Combining Theory, Model, and Experiment to Explain How Intrinsic Theta Rhythms Are Generated in an In Vitro Whole Hippocampus Preparation without Oscillatory Inputs. eNeuro 2017, 4. [CrossRef] [PubMed]

9. Grillini, L.L.; Affatato, S. How to measure wear following total hip arthroplasty. Hip Int. 2013, 23, $233-242$. [CrossRef] [PubMed]

10. Banaszkiewicz, P.A. Effect of femoral head size on wear of the polyethylene acetabular component. In Classic Papers in Orthopaedics; Springer: Berlin, Germany, 2014; ISBN 9781447154518.

11. Livermore, J.; Ilstrup, D.; Morrey, B. Effect of femoral head size on wear of the polyethylene acetabular component. JBJS 1990, 72, 518-528. [CrossRef]

12. Kabo, J.M.; Gebhard, J.S.; Loren, G.; Amstutz, H.C. In vivo wear of polyethylene acetabular components. J. Bone Jt. Surg. 1993, 75, 254-258. [CrossRef]

13. Sofka, C.M.; Potter, H.G.; Figgie, M.; Laskin, R. Magnetic Resonance Imaging of Total Knee Arthroplasty. Clin. Orthop. Relat. Res. 2003, 129-135. [CrossRef] 
14. West, J.; Romu, T.; Thorell, S.; Lindblom, H.; Berin, E.; Holm, A.C.S.; Åstrand, L.L.; Karlsson, A.; Borga, M.; Hammar, M.; et al. Precision of MRI-based body composition measurements of postmenopausal women. PLoS ONE 2018. [CrossRef] [PubMed]

15. Hellmanns, K.; McBean, K.; Thoirs, K. Magnetic Resonance Imaging in the measurement of whole body muscle mass: A comparison of interval gap methods. Radiography 2015, 21, e35-e39. [CrossRef]

16. Brinke, B.T.E.N.; Beumer, A.; Koenraadt, K.L.M.; Eygendaal, D.; Kraan, G.A.; Mathijssen, N.M.C. The accuracy and precision of radiostereometric analysis in upper limb arthroplasty-A systematic review of 23 RSA studies. Acta Orthop. 2017, 88, 320-325. [CrossRef]

17. Holm-Glad, T.; Reigstad, O.; Tsukanaka, M.; Røkkum, M.; Ro€hrl, S.M. High Precision and Accuracy of Model-Based RSA for Analysis of Wrist Arthroplasty. J. Orthop. Res. 2018, 36, 3053-3063. [CrossRef] [PubMed]

18. Önsten, I.; Berzins, A.; Shott, S.; Sumner, D.R. Accuracy and precision of radiostereometric analysis in the measurement of THR femoral component translations: Human and canine in vitro models. J. Orthop. Res. 2001, 19, 1162-1167. [CrossRef]

19. Ranstam, J.; Ryd, L.; Onsten, I. Accurate accuracy assessment: Review of basic principles. Acta Orthop. Scand. 2000, 71, 106-108. [CrossRef]

20. Seehaus, F.; Emmerich, J.; Kaptein, B.L.; Windhagen, H.; Hurschler, C. Dependence of model-based RSA accuracy on higher and lower implant surface model quality. Biomed. Eng. Online 2013, 12, 1-14. [CrossRef]

21. Selvik, G. A stereophotogrammetric system for the study of human movements. Scand. J. Rehabil. Med. Suppl. 1978, 6, 16-20.

22. Johnston, C.; Kerr, J.; Ford, S.; O’Byrne, J.; Eustace, S. MRI as a problem-solving tool in unexplained failed total hip replacement following conventional assessment. Skelet. Radiol. 2007. [CrossRef]

23. Kurtz, S.; Ong, K.; Lau, E.; Mowat, F.; Halpern, M. Projections of primary and revision hip and knee arthroplasty in the United States from 2005 to 2030. J. Bone Jt. Surg. Am. 2007, 89, 780-785. [CrossRef]

24. Kurtz, S.; Ong, K.L.; Schmier, J.; Mowat, F.; Saleh, K.; Dybvik, E.; Kärrholm, J.; Garellick, G.; Havelin, L.I.; Furnes, O.; et al. Future clinical and economic impact of revision total hip and knee arthroplasty. J. Bone Jt. Surg. Am. 2007, 89 (Suppl. 3), 144-151. [CrossRef]

25. Kurtz, S.M.; Lau, E.; Watson, H.; Schmier, J.K.; Parvizi, J. Economic burden of periprosthetic joint infection in the united states. J. Arthroplast. 2012. [CrossRef] [PubMed]

26. Dowson, D. History of Tribology, 2nd ed.; Wiley Blackwell: London, UK, 1998.

27. Collins English Dictionary-Complete and Unabridged Invitro.pdf. Available online: https://www. thefreedictionary.com/in+vitro (accessed on 6 May 2020).

28. Affatato, S.; Spinelli, M.; Zavalloni, M.; Mazzega-Fabbro, C.; Viceconti, M. Tribology and total hip joint replacement: Current concepts in mechanical simulation. Med. Eng. Phys. 2008, 30, 1305-1317. [CrossRef] [PubMed]

29. ASTM F2003. ASTM F2003-02(2015) Standard Practice for Accelerated Aging of Ultra-High. Molecular Weight Polyethylene after Gamma Irradiation in Air; ASTM International: Conshohocken, PA, USA, 2003.

30. ISO DIS 14242-1 Implants for Surgery-Wear of Total Hip-Joint Prostheses_Part 1: Loading and Displacement Paramenters for Wear-Testing Machines and Corresponding Environmental Conditions for Test; ISO International: Geneva, Switzerland, 2012.

31. ISO-4243/3. ISO ISO 14243-3:2014(en), Implants for Surgery-Wear of Total Knee-Joint Prostheses-Part 3: Loading and Displacement Parameters for Wear-Testing Machines with Displacement Control and Corresponding Environmental Conditions for Test; ISO International: Geneva, Switzerland, 2004.

32. Abdel-Jaber, S.; Belvedere, C.; De Mattia, J.S.; Leardini, A.; Affatato, S. A new protocol for wear testing of total knee prostheses from real joint kinematic data: Towards a scenario of realistic simulations of daily living activities. J. Biomech. 2016, 49. [CrossRef] [PubMed]

33. Affatato, S. Towards wear testing of high demanding.pdf. J. Braz. Soc. Mech. Sci. Eng. 2018, 40, 260-266. [CrossRef]

34. Brockett, C.; Williams, S.; Jin, Z.; Isaac, G.; Fisher, J. Friction of Total Hip Replacements With Different Bearings and Loading Conditions. J. Biomed. Mater. Res. B Appl. Biomater. 2006, 81, 508-515. [CrossRef]

35. Dowson, D. New joints for the Millennium: Wear control in total replacement hip joints. Proc. Inst. Mech. Eng. H 2001, 215, 335-358. [CrossRef]

36. Affatato, S.; Zanini, F.; Carmignato, S. Micro X-ray computed tomography mass loss assessment of different UHMWPE: A hip joint simulator study on standard vs. cross-linked polyethylene. PLoS ONE 2017, 12, e0170263. [CrossRef] 
37. Affatato, S.; Valigi, M.C.; Logozzo, S. Wear distribution detection of knee joint prostheses by means of 3D optical scanners. Materials 2017, 10, 364. [CrossRef]

38. Tunev, S.S. Differences between in Vitro, in Vivo, and in Silico Studies in Vitro Studies in Vivo Studies in Silico Studies Read. The Marshall Protocol. Autoimmunity Research Foundation. Available online: https://mpkb.org/home/patients/assessing_literature/in_vitro_studies (accessed on 7 September 2020).

39. Sirakoulis, G.C.; Karafyllidis, I.; Mizas, C.; Mardiris, V.; Thanailakis, A.; Tsalides, P. A cellular automaton model for the study of DNA sequence evolution. Comput. Biol. Med. 2003, 33, 439-453. [CrossRef]

40. Sieburg, H.B. Physiological studies in silico. In Lectures in Complex Systems, SFI Studies in the Sciences of Complexity; Nadel, L., Stein, D., Eds.; Addison-Wesley: San Diego, CA, USA, 1991; Volume 3, pp. 367-390.

41. Ruggiero, A.; Sicilia, A. Lubrication modeling and wear calculation in artificial hip joint during the gait. Tribol. Int. 2020, 142, 1-16. [CrossRef]

42. Ruggiero, A.; D'Amato, R.; Affatato, S. Comparison of meshing strategies in THR finite element modelling. Materials 2019, 12, 2332. [CrossRef] [PubMed]

43. Ruggiero, A.; Merola, M.; Affatato, S. Finite element simulations of hard-on-soft hip joint prosthesis accounting for dynamic loads calculated from a Musculoskeletal model during walking. Materials 2018, 11, 574. [CrossRef] [PubMed]

44. Affatato, S.; Merola, M.; Ruggiero, A. Development of a novel in silico model to investigate the influence of radial clearance on the acetabular cup contact pressure in hip implants. Materials 2018, 11, 1282. [CrossRef] [PubMed]

45. Abdel-Jaber, S.; Belvedere, C.; Leardini, A.; Affatato, S. Wear simulation of total knee prostheses using load and kinematics waveforms from stair climbing. J. Biomech. 2015, 48, 3830-3836. [CrossRef]

46. Ruggiero, A.; Sicilia, A.; Affatato, S. In silico total hip replacement wear testing in the framework of ISO 14242-3 accounting for mixed elasto-hydrodynamic lubrication effects. Wear 2020, 460-461, 203420. [CrossRef]

47. Azpiroz-Zabala, M.; Storms, J.; Van Der Vegt, H.; Walstra, D. A numerical model of a 3-dimensional low-density turbidity current in the deep ocean: Testing hypotheses on turbidity currents in deep detail. Geophys. Res. Abstr. 2019, 21, 8459.

48. Christie, M.J.; Barrington, S.A.; Brinson, M.F.; Ruhling, M.E.; DeBoer, D.K. Bridging massive acetabular defects with the triflange cup: 2- to 9-year results. Clin. Orthop. Relat. Res. 2001, 393, 216-227. [CrossRef]

49. Ruggiero, A. Milestones in natural lubrication of synovial joints. Front. Mech. Eng. 2020, 10. [CrossRef]

50. Archard, J.F. Contact and rubbing of flate surfaces. J. Appl. Phys. 1953, 24, 981-988. [CrossRef]

51. Mazzucco, D.; Spector, M. Effects of contact area and stress on the volumetric wear of ultrahigh molecular weight polyethylene. Wear 2003, 254, 514-522. [CrossRef]

52. Kang, L.; Galvin, A.L.; Fisher, J.; Jin, J. Enhanced computational prediction of polyethylene wear in hip joints by incorporating cross-shear and contact pressure in additional to load and sliding distance: Effect of head diameter. J. Biomech. 2009, 42, 912-918. [CrossRef] [PubMed]

53. O'Brien, S.T.; Luo, Y.; Brandt, J.M. In-vitro and in-silico investigations on the influence of contact pressure on cross-linked polyethylene wear in total knee replacements. Wear 2015. [CrossRef]

54. O’Brien, S.T.; Bohm, E.R.; Petrak, M.J.; Wyss, U.P.; Brandt, J.-M. An energy dissipation and cross shear time dependent computational wear model for the analysis of polyethylene wear in total knee replacements. J. Biomech. 2014. [CrossRef] [PubMed]

55. Kim, S.H.; Asay, D.B.; Dugger, M.T. Nanotribology and MEMS. Nano Today 2007, 2, 22-29. [CrossRef]

56. Bhushan, B. Nanotribology and nanomechanics. Wear 2005. [CrossRef]

57. Tzanakis, I.; Hadfield, M.; Thomas, B.; Noya, S.M.; Henshaw, I.; Austen, S. Future perspectives on sustainable tribology. Renew. Sustain. Energy Rev. 2012, 16, 4126-4140. [CrossRef]

58. Zhou, Z.R.; Jin, Z.M. Biotribology: Recent Progresses and Future Perspectives. Biosurf. Biotribol. 2015, 1, 3-24. [CrossRef]

59. Cann, P.; Wimmer, M. Welcome to the first issue of Biotribology. Biotribology 2015. [CrossRef]

60. Martin, J.M.; Donnet, C.; Le Mogne, T.; Epicier, T. Superlubricity of molybdenum disulphide. Phys. Rev. B 1993. [CrossRef]

61. Wang, L.; Zhou, X.; Ma, T.; Liu, D.; Gao, L.; Li, X.; Zhang, J.; Hu, Y.; Wang, H.; Dai, Y.; et al. Superlubricity of a graphene/MoS2 heterostructure: A combined experimental and DFT study. Nanoscale 2017. [CrossRef] [PubMed]

62. Berman, D.; Deshmukh, S.A.; Sankaranarayanan, S.K.R.S.; Erdemir, A.; Sumant, A.V. Macroscale superlubricity enabled by graphene nanoscroll formation. Science 2015. [CrossRef] [PubMed] 
63. Vakis, A.; Yastrebov, V.; Scheibert, J.; Minfray, C.; Nicola, L.; Dini, D.; Almqvist, A.; Paggi, M.; Lee, S.; Limbert, G.; et al. Modeling and simulation in tribology across scales: An overview. Tribol. Int. 2018, 125, 1-83. [CrossRef]

64. Morrison, T.M.; Pathmanathan, P.; Adwan, M.; Margerrison, E. Advancing regulatory science with computational modeling for medical devices at the FDA's office of science and engineering laboratories. Front. Med. 2018. [CrossRef] [PubMed]

65. TMorrison, T.M. Innovations in modeling and simulation: Patient-centered healthcare. Ann. Biomed. Eng. 2016, 44, 3719-3721. Available online: http://rug.on.worldcat.org/atoztitles/link/?sid=EMBASE\&issn= 15739686\&id=doi:10.1007\%2Fs10439-016-1710-7\&atitle=Innovations+in+modeling + and + simulation \% $3 \mathrm{~A}+$ Patient-centered + healthcare\&stitle $=$ Ann+Biomed + Eng\&title $=$ Annals + of + Biomedical + Engineering\& volume $=44 \&$ issue $=12 \&$ spage $=3719 \&$ epage $=3721 \&$ aulast $=$ Morrison\&aufirst $=$ Tina + M $\&$ auinit $=$ T.M.

\&aufull=Morrison+T.M.\&coden=\&isbn=\&pages=3719-3721\&date=2016\&auinit1=T\&auinitm =M (accessed on 7 September 2020). [CrossRef]

66. Ruggiero, A.; Zhang, H. Editorial: Biotribology and Biotribocorrosion Properties of Implantable Biomaterials. Front. Mech. Eng. 2020, 6. [CrossRef]

67. Shi, L.; Guo, Z.; Liu, W. The recent progress of tribological biomaterials. Biosurf. Biotribol. 2015, 26. [CrossRef]

(C) 2020 by the authors. Licensee MDPI, Basel, Switzerland. This article is an open access article distributed under the terms and conditions of the Creative Commons Attribution (CC BY) license (http://creativecommons.org/licenses/by/4.0/). 